\title{
TOCANDO A PELE DA ESCRITA: \\ LINHAS DE NÓS-BRASIL E NÓS-ÁFRICA
}

RESUMO: Pensando em estações e ideias que lembram afetos, este artigo tem por objetivo apresentar experiências com escritas literárias por estradas que mobilizaram caminhos do Atlântico sul a partir de uma oficina realizada no ano de 2016 - que, intitulada Escrever pra quê?, foi vivenciada por alunas/os do Brasil, São Tomé e Príncipe e Guiné-Bissau, na Universidade da Integração Internacional da Lusofonia Afro-Brasileira (Unilab-CE). Passeando por discussões em torno de políticas de escrita e ato de escrever (RANCIÈRE, 2017; DELEUZE; GUATTARI, 2011), leitura (ZUMTHOR, 2014), literatura oral (CASCUDO, 1978; ALMEIDA, 2009), poética (BARROS, 2010) e lusofonia (BRITO; BASTOS, 2006), este estudo teórico-reflexivo procurou problematizar os matizes metodológicos e vivenciais dessa oficina acolhidos na ideia de construção de "linhas de fuga" e linhas de convivência atravessadas e partilhadas por experiências com a escrita e o medo de escrever ao longo da trajetória literária de um grupo de escritoras/es.

PALAVRAS-CHAVE: Escrever; Escrita; Leitura; Medo.

Toda escrita tem sua temperatura. Às vezes vaporiza, por outras congela. Mas ela está ali. A escrita está mesmo latente numa ainda-ideia. Escritas universalizam singularidades e singularizam universos. Não precisamos ter medo. O medo de escrever caminha de mãos dadas com o medo de pensar, o que me faz lembrar as palavras do poeta Carlos Drummond de Andrade, que disse: “(...) E fomos educados para o medo./Cheiramos flores de medo.

\footnotetext{
* Professora-pesquisadora do Instituto de Humanidades da Universidade da Integração Internacional da Lusofonia Afro-Brasileira (Unilab-CE) e do Programa de Pós-Graduação em Artes, da Universidade Federal do Ceará (UFC).
} 
/Vestimos panos de medo./(...) O medo, com sua capa, nos dissimula e nos berça./(...) O medo, com sua física, tanto produz: carcereiros, edifícios, escritores, este poema, outras vidas (ANDRADE, 2000, p. 25-28). O medo se instala e nos penumbra, por vezes. Imobiliza-nos? O que realmente tocamos diante do medo de escrever?

Ora, quando escrevemos não nos separamos do que vivemos. E a vida, tecida em experiências de palavras e imagens, também faz caminhos de ignorância, pois "não há ignorante que já não saiba um monte de coisas, que não as tenha aprendido sozinho, olhando e ouvindo o que há ao seu redor, observando e repetindo, enganando-se e corrigindo seus erros" (RANCIÈRE, 2012, p. 13-14). Fazer caminhos de ignorâncias é "apalpar as intimidades do mundo" (BARROS, 2010, p. 299), sem medo; ignorâncias tendem a ser o alvo de correção nas escolas, universidades, instituições de ensino - e esquecemos que as ignorâncias (que não são todas iguais) também têm sabedorias. Foi em Manoel de Barros (2010, p. 300) que comecei a coser alguns tec(er)idos de ignorâncias: ignorâncias de invenção, quando é possível "usar algumas palavras que ainda não tenham idioma"; ignorâncias de inclusão, que "é quando um trevo assume a noite/E um sapo engole as auroras"; ignorâncias de (des)caminhos, nos momentos em que "formigas-carregadeiras entram em casa de bunda". E há tantas mais ignorâncias no mundo para se descobrirem ignorãças, que é possível refazer/desfazer a rotina de correção nas escolas, universidades, instituições de ensino. Dessa maneira: escrevemos - porque podemos fazer esses caminhos, mesmo quando não sabemos dominar as (des)codificações e interpretações da escrita gramatical.

$\mathrm{O}$ ato de escrever é, antes de tudo, o ato de imaginar com/pelo corpo, e "o corpo é o peso sentido na experiência que faço dos textos. Meu corpo é a materialização daquilo que me é próprio, realidade vivida e que determina minha relação com o mundo" (ZUMTHOR, 2014, p. 27). O pensamento, que também é corpo, ou pensamento-corpo é a terra onde nasce a escrita feita frase, argumento, discurso: o poeta cearense Patativa do Assaré que afirmou "não tenho sabença, pois nunca estudei/Apenas eu sei meu nome assiná" (ASSARÉ, 2007, p. 21) bem o sabia; Patativa escrevia com a imaginação das palavras em "verso rastêro" de pensamentos: 
Cresci entre os campos belos

De minha adorada Serra

Compondo versos singelos

Brotados da própria terra,

Inspirado nos primores

Dos campos com suas flores

De variados formatos

Que pra mim são obras-primas,

Sem nunca invejar as rimas

Dos poetas literatos.

(ASSARÉ, 2001, p. 67)

Assim como Patativa, ao escrever junto minha inteligência integral com a inteligência integral do outro: construo uma política do ato de escrever. E escrever é sempre um ato político. Se temos medo de escrever é porque, de alguma forma, também temos receio das barricadas que nos constroem como sujeitos, seres-políticos em disputa de espaços com o mundo. "Escrever é um ato que, aparentemente, não pode ser realizado sem significar, ao mesmo tempo, aquilo que realiza (...), antes de ser o exercício de uma competência, o ato de escrever é uma maneira de ocupar o sensível e dar sentido a essa ocupação" (RANCIÈRE, 2017, p. 07). O medo de escrever, dessa forma, é também o processo de afastamento do sensível que se dá, reverberado, em muitas frases do tipo "e se eu escrever errado", "e se ninguém entender", "ninguém gosta do que eu escrevo”, “deu um branco", "prefiro falar a escrever" etc-etc-etc.

E o que significa escrever, então? Ter domínio das regras gramaticais é um passo importante, mas o é mais do que deveria ser; escrever nasce no pensamento e no corpo, mesmo quando ainda não domino a técnica sintagmática das redes de signos. A oralidade literária é rica em experiências de escritas construídas com pensamento-corpo, ritmo, imagem, performance, emoção: "por que não pensar a escrita como vias de passagem onde as redes se formam?" (ALMEIDA, 2009, p. 52); ora, para chegarmos ao desenho da letra, mesmo aquela que escolhemos no computador, passeamos pela não-escrita da escrita porque as palavras são vivas, em si, e nos espaços vazios entre-si. $\mathrm{O}$ ato de escrever vai além 
do efeito de significar, excedendo-se por fronteiras e camadas semióticas-políticas-culturais-econômicas-sociais (DELEUZE; GUATTARI, 2011). A escrita não acontece sem a não-escrita elaborada pelo pensamento-corpo que forma palavras e as inaugura em signos que dançam em senões. É enganoso pensar, portanto, que o conhecimento de regras gramaticais subsiste como substrato único para o ato de escrever; as regras gramaticais são conhecimentos de lei da escrita, mas não são a totalidade da escrita em si.

\author{
Nain remou de uma piranha. \\ Ele pegou um pau, pum!, \\ Na parede do jacaré... \\ Veio Maria-preta fazeu três araçás pra mim. \\ Meu bolso teve um sol com passarinhos. \\ (BARROS, 2010, p. 95)
}

Naim, jacaré, Maria-preta e passarinhos são fermentos de escritas, porque escrita é o sensível, a palavra feita a partir de poéticas de sensações, enredos e experiências; escrita é aquilo que quebra as regras para dizer por que "fazeu três araçás pra mim": ação de liberdade do pensamento-corpo.

Também é importante dizer que a escrita, assim como a leitura, acontece em estações, pois "o próprio da escrita é, a cada frase, parar para recomeçar" (BENJAMIN, 2016, p. 17): vem, volta, para, dorme, elastiza. Walter Benjamin usa a palavra "estação" para falar do movimento leitura-escrita - a influência etimológica da palavra "estação" é statiõ (do latim), lugar fixo, mas também morada, guarnição, situação, que se dão na relação com o tempo. Deter-se em estações parece-se com o construir paragens, abrigos, fluxos de tempo que se realizam no ato da escrita e da leitura (que são, em si, dois atos inseparáveis: leio-me enquanto escrevo e escrevo enquanto me leio): portanto, escrever é frequentar estações. As estações, que são paragens de ideias e estas, por sua vez, "constelações eternas" (BENJAMIN, 2016, p. 23), desabrigam a fixidez enrijecedora do medo. 
Foi assim, pensando em estações e ideias que lembram afetos, que partilho as experiências com escritas por estradas que mobilizaram caminhos do Atlântico sul. Falo, especificamente, da Oficina ${ }^{1}$ Escrever pra quê??, vivenciada no ano de 2016, com alunas/os do Brasil, São Tomé e Príncipe e Guiné-Bissau. A ideia inicial dessa Oficina, organizada pelo Atelię2, era de exercitar escritas literárias a partir do gênero "contos" com metodologias que fizessem circular, coletivamente, as vivências de escritas ao longo do trajeto do grupo de escritoras/es; imbuído desta intenção, o Ateliê lançou um convite público para todos/as que se interessassem em fazer parte de um projeto de encontros presenciais quinzenais na Universidade da Integração Internacional da Lusofonia Afro-brasileira (Unilab-CE), intermediados por acompanhamentos/desafios dos/aos processos de escritas via e-mails. Para partilhar com mais profundidade os caminhos de escritas que fizemos ao longo dos encontros, vou dividir esse artigo em estações (ao modo de Benjamin) de afetos, partilhas e leitores/as.

\section{Estação de afetos}

Diz Didi-Huberman (2011, p. 11) que "Dante quis reservar, no vigésimo sexto canto do Inferno, um destino discreto, embora significativo, à "pequena luz" (Lucciola) dos pirilampos, dos vaga-lumes". Os afetos com a escrita são como essas chamas acesas que se movem incessantemente no Inferno de Dante, vaga-lumes do reconhecimento de si e tão pouco acolhidos. Como poderei desejar que alguém me leia se eu mesma/o resisto em fazêlo? De que maneira chegarei a acreditar nas leituras que de meus textos fizeram/fazem se sou desditosa/o com o que consigo realizar? Os afetos com a própria escrita dão-se, a meu ver, como "seres luminescentes, dançantes, erráticos, intocáveis e resistentes” (DIDI-HUBERMAN, 2011, p. 23), abismos que vão fermentando, agregando, destruindo, criando

\footnotetext{
${ }^{1}$ Que passarei a denominar no decorrer do artigo apenas por "Oficina”.

${ }^{2} \mathrm{O}$ Ateliê é um Grupo de Pesquisa e Estudos Interartes, cadastrado no CNPq, sob a coordenação das professoras Jo A-mi e Rosália Menezes. E-mail: atelieunilab@gmail.com
} 
outros lugares-próprios-de-escrita que ultrapassam a repetição de modelos e serões padronizados. Rabiscar, escrever, papel guardado, arquivo de computador, anotações no canto de folha: o que eu quero dizer? Dar-se a liberdade de dizer tem sido um passo importante para escrever. Para tal, propus como metodologia que o grupo caminhasse sobre alguns abismos: a experiência de escrita fora da "inspiração" foi um deles. O conto-crônica Escrever pra quê?, do escritor guineense Ianes Cá, intervém: "Registrar uma história? Um acontecimento? Ou manufaturar o acontecimento que chamamos de ficção? (CÁ, I., 2016, p. 16).

As perguntas chegavam suadas. Em quinze dias cada um/a traria seu texto. Com tempo, sem tempo, destemperado. Recebi alguns e-mails que reclamavam: "escrever com prazo não vai funcionar" ou "só consigo escrever quando estou inspirado/a".

Todo mundo suando agora! Será que todo mundo tem essa habilidade? Eu não tenho, mas eu vou escrever alguma coisa. Comecei com uns pensamentos malucos, sem raciocínio, mas do meu domínio; sem graça, mas de esperança. Colocava no papel toda palavra que vinha à minha mente. Eu não me importava com a métrica, porque não tinha metro. Comecei a transpirar. (CÁ, I., 2016, p. 19)

A transpiração foi um abismo fundamental que atravessamos no processo de escrita da Oficina; desfazer os caminhos de escrita essencialmente aprendidos/realizados por inspiração pelos/as participantes consistiu num desafio contínuo de trabalho com o texto em suas diversas ramificações (estética, estilística, imagética etc.). Os afetos com a própria escrita deram-se, portanto, mediados pelo ato do escrever como experiência contínua cotidiana: entreolhando-se como espelhos de escrita, lugares de dentro e de fora em imagens que se avistaram em (nossas) janelas; os afetos da escrita passaram, assim, pelo trabalho que apaga, que deleta, que pesquisa, que orquestra caminhos. Mesmo sem saber, mesmo com medo, o grupo se desafiou a expressar pensamentos-corpo sem metros ou inspiração.

\section{Estação de partilhas}

A Oficina, contudo, guardava uma particularidade desafiante: abrigar experiências culturais, linguísticas, sociais amplas performatizadas num território bastante complexo: a 
Unilab. Aqui, grupo de nações aglomeram-se em corredores e espaços de convivência. Há Moçambique, Cabo Verde, Guiné-Bissau, Brasil, Angola, São Tomé e Príncipe, TimorLeste. Integram-se? Todos estão lá falando as suas línguas e a língua de todos - com sotaques de língua portuguesa que reverberam diversos assuntos. Integram-se? As escadas, as salas de aula, as coordenações, as mesas de reuniões ouvem melodias que gritam, cantam, brigam, conversam. Integram-se? $\mathrm{O}$ atlântico separa meninos e meninas africanos de suas famílias, pertencentes a países parceiros da Comunidade dos Países de Língua Portuguesa (CPLP), para fazê-los conviver no nordeste do Brasil: lugares cuja marca da desigualdade social tem intensas redes de conexão (GOMES; VIEIRA; 2013). Integram-se? As repetidas interrogativas vêm como um sino a fustigar o cotidiano que frequento. E quando procuro pelas frestas sinonímicas de "integração" acho tantas possibilidades: integração advém de integrar, que, por sua vez, é “completar", etimologicamente (CUNHA, 2001). Integrar é também aproximar, acomodar, adaptar, incorporar, assimilar, participar, compor, constituir, formar (DICIONÁRIO HOUAISS, 2008). O que queremos integrar, nós-Brasil e nósÁfrica, convivendo entre vestes multicoloridas do sul-sul?

Bem, a discussão sobre integração entre países que se expressam pela língua portuguesa passa pelo conceito de lusofonia - parte, inclusive, da inscrição identitária da Unilab; embora não tenha a pretensão de me aprofundar sobre o conceito de lusofonia, aqui, posso dizer que este está longe de ser algo consensual entre os chamados "países parceiros". Por um lado, temos na lusofonia a proposição de três princípios gerais (BRITO; BASTOS, 2006): 1) Globalização: que ultrapassa as fronteiras linguísticas para formar uma "identidade comunitária" entre países; 2) Diversificação: no reconhecer da forte heterogeneidade das realidades vivenciadas por cada nação; 3) Relativização: que, diante da diversificação de cada integrante em sua relação com o mundo globalizado, tende a ser pouco coesa e desigual. Os/as defensores da ideia de uma lusofonia abrangente e real veem a língua portuguesa como um motor estratégico para economias e trocas culturais, lugar de "unidade nacional" a nos inserir no mundo globalizado. 
Por outro lado, falar em lusofonia - cuja memória etimológica remete-nos à Lusitânia (província da Hispânia) e a luso (relativo a Portugal) - pode contribuir para uma afirmação de Portugal e seus lugares de poder no mundo globalizado. Assim,

para os povos que foram colonizados não pode ser simples dissociar o passado histórico colonial do sentido que ensinam os dicionários: o termo lusófono aplica-se aos indivíduos que têm em comum a Língua Portuguesa e que partilham elementos culturais e históricos. (BRITO; BASTOS, 2006, p. 72)

O historiador angolano Carlos Pacheco, no artigo Lusofonia e regimes autoritários em Africa (2000), aprofunda as pontes críticas sobre os usos do termo lusofonia afirmando-o como "chavão" e "arma de arremesso" portugueses:

chavão que, desde a sua criação, tem servido para mascarar a realidade dos factos e que grupos de influência em Portugal, no aparelho de Estado e fora dele, aproveitam como arma de arremesso para fazer vingar propósitos menos claros. Está visto que a lusofonia não passa de um conceito vago, uma estratégia política e cultural sem qualquer correspondência com a alma e o sentir dos povos africanos. Incluindo o Brasil.

Penso que uma parte dessa problematização - não da resposta, pois não precisamos tanto de certezas e fins - passa pelas (in)tensas "linhas de fuga"; linhas de fuga que são uma forma de agenciamento, ou seja, “crescimento das dimensões numa multiplicidade que muda necessariamente de natureza à medida que ela aumenta suas conexões" (DELEUZE; GUATTARI; 2011, p. 24). Nenhuma cooperação internacional foi/é capaz de limitar o emaranhado de linhas construídas nos processos de integração nós-Brasil e nós-África dadas no cotidiano; e quando piso sobre a bamba-corda da integração nas universidades e, com especial atenção, à realidade em construção na Unilab, percebo que costuramos

(...) cotidianamente o desafio de reconhecimento da diversidade e do trato ético e pedagógico dos sujeitos diversos e produtores de conhecimento. O desafio é o de se tornar, no contexto da cooperação internacional Sul-Sul, um centro de produção do conhecimento 
que realize um diálogo horizontal - e não menos tenso - entre culturas, valores e projetos de sociedade. E, além disso, o desafio de articular e ultrapassar o plano do local para o global, do regional para o nacional, do nacional para o internacional e de um só continente para o intercontinental. Um projeto político e acadêmico que vem sendo construído por gestores, docentes, discentes, corpo técnicoadministrativo e comunidade (GOMES; VIEIRA; 2013, p. 86).

As linhas de aproximação e composição na Oficina, mais especificamente, o processo de integração de línguas, culturas, corpos, tempos, criação foi gerando e sendo gerado ao longo da estação de partilhas dos textos. Com uma metodologia que consistia na partilha coletiva dos textos escritos, a cada quinze dias, reuníamo-nos para apresentar nossos enredos. Cada escritor/a-leitor/a lia o que escrevia com palavras e imagens a-fronteiriças; ali, íamos acomodando muitos territórios: do gesto erótico dos corpos desejantes do escritor brasileiro Carlos Eduardo Pinheiro, no conto Entre lencóis:

Experimento o toque perigoso das tuas mãos tracejando, suavemente, linhas e círculos nas minhas costas. Naquele instante, sou todo medo e desejo. (...) Do outro lado das paredes dorme um casal de universitários; no corredor, em frente ao nosso quarto, um filhote de vira-lata brinca com um pote de ração vazio; na sala, uma rede de renda balança solitária conduzida pela brisa da madrugada. O cheiro de chuva permanece impregnado na casa há horas; o silêncio das ruas desaparece no quarto, mas a escuridão é a mesma. (PINHEIRO, 2016, p. 79-80)

Aos imaginários guineenses na voz de João Fernando Cá com Um precisa do outro, temperados por rítmicas da literatura oral amplamente vivenciada por numerosas gerações nos países africanos - assim como numerosas gerações de brasileiros viventes das florestas em clima equatorial (na região norte do país), passando pelos sertões e caatingas do nordeste até aos pampas do extremo sul: "todos sabiam contar estórias. Contavam à noite, devagar, com gestos de evocação e lindos desenhos mímicos com as mãos" (CASCUDO, 1978, p. 13). Nesse conto, encontramos a narrativa de vida dos amigos Arnaldo e Paulo, moradores da cidade de Binde; de classes sociais antagônicas e enfrentando as admoestações dos pais 
sobre a nascente amizade, os personagens lutam para reconfigurar as relações sociais vigentes em sua sociedade:

Os dois, satisfeitos, apertaram-se no jeito de solidariedade. Conheceram-se e passaram a sobreviver aliados (...). Brincaram e se formaram juntos. Casaram com suas mulheres e fizeram juras de jamais se separarem daquele consórcio até à morte. (CÁ, J., 2016, p. 36-38)

No contexto de partilha das escritas nessa estação, dessa forma, fomos construindo obras. Obras que não se pretendiam ou limites ou limitadas ou limitantes, mas "investigação artística, enquanto prática contínua não sujeita a um ponto de partida ou de chegada", nem aquém nem além da Oficina, mas um encontro em que pudemos trocar "essas linhas/manchas, essas configurações efémeras que são a potência da criação" (NEUPARTH, 2011, p. 19). Criando processos de convivência, os contos literários tornaram-se construção do espelho da escrita, desenhando sensações/impressões que se enredaram no texto-leitura do outro.

\section{Estação de leitores/as}

O texto-leitura do outro passa pela partilha. Leitores partilham experiências de leituras escutando palavras, sons, desenhos, cheiros, sabores. Griots, avós, cantadores, artistas, livros, vídeos, quadrinhos, sonhos oferecem/ofereceram-nos leituras continuamente. A ideia de sentar e ouvir e olhar para cada participante da Oficina foi, além de uma tentativa de subverter aporias, a possibilidade de viver o escrito do outro desde a performance das leituras à estrutura de texto/palavras construídas. Por vezes, nossa imaginação aconchegava-se no terreiro, luz do sol escorregando pela lateral dos olhos, vento na face; sensações que vinham, principalmente, em contos como O menino que contrariou a lua, da escritora santomense Silvia Will, quando o fascínio de lendas e histórias construídas durante a trajetória pessoal da escritora, em São Tomé e Príncipe, (re)fazem-se em narrativas de memórias-deser-de-um-lugar pela linha da ficção. Nesta, a luz da lua faz girar em força centrípeta uma coletividade que só banha, come, festeja após o nascimento do brilho da lua. Um dia, a 
"ordem natural" das coisas se desfaz em acontecimentos e sentimentos através do nascer de uma criança que ousara vir ao mundo "antes de a lua surgir no céu":

No tempo em que São Tomé não tinha nome era conhecida como ilha da lua e todos tinham um desejo - o de ver seus sonhos tornarem-se realidade. Ninguém naquela pequena ilha sabia ao certo por que esta tinha aquele nome. Uns diziam que a ilha talvez tivesse a forma de lua, mas não podiam afirmar porque nenhum morador vira a ilha do lado de cima. Outros diziam que tudo ali acontecia só depois de a lua surgir no céu. (...) Porém, um dia, algo estranho aconteceu: já o sol brilhava no céu quando a Sra. Maku, a parteira mais sábia de toda ilha, foi chamada. Os seus cabelos eram brancos como a lua nova e era hábito dizer-se que tinha a idade da lua. Ninguém sabia a sua idade nem quantos partos já fizera. A parteira entrou na velha casa com o formato de lua, ainda incrédula no que os seus olhos viam. (WILL, 2016, p. 39-40)

Por outras vezes, aprendemos com a ingenuidade, singeleza, doçura do canto da criança de um conto como IVO, da brasileira Mykele Dodó; com a sabedoria de uma criança, Ivo não conseguia entender as (in)utilidades da vida das gentes adultas. Construindose num diálogo silencioso entre Ivo, caderno-narrador e desenhos da autora, essa narrativa trouxe para a Oficina algo em torno de um "saber sobre as coisas insignificantes da vida" (A-MI, 2016, p. 12), problematizando-a em variadas dimensões - especialmente diante de nossos engessamentos acadêmicos e culturais:

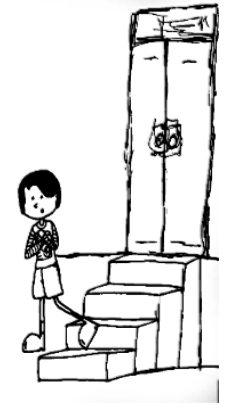

Ivo era um garotinho que nunca entendia o que lhe ensinavam. (...) Acredito que justamente por ser inteligente demais é que Ivo não conseguia entender os ensinamentos dos adultos. Ele sempre tentava fazer as coisas do jeito certo - digo isso porque o via tentar. Mas não importava o que fizesse, ele simplesmente não conseguia entender nada direito. (...) Ivo era muito curioso, adorava brincar de descobrir. Antes de ele começar a ir à escola, Mamãe achava isso fantástico; mas aí o menino aprendeu a contar depois de 100 e decidiu descobrir quantos feijões cabiam dentro do pote da cozinha. Ela deu a maior bronca nele e a gente foi ficar triste no quarto tentando descobrir o que havia feito de errado. Nesse dia, as lágrimas de Ivo, que descobrira não ser capaz de entender o mundo, atravessaram minhas fibras e foi como se eu também pudesse sentir um pouco da dor que o pequeno sentia naquele coraçãozinho frágil. Na verdade, o mundo é que não o compreendia. (DODÓ, 2016, p. 29-30) 


\section{Conclusões: fim da linha?}

O medo pode nos fixar numa estação, o afeto com a própria escrita desmobiliza a fixidez. A escrita como afeto e os lugares de transpiração/partilha/leitura foram abismos que mobilizamos contra o medo de escrever, levando-nos a estações, estações, estações. Nas estações da Oficina (des)inventamos ideias, ideias de amor, de beleza, de dor, de sofrimento, de delicadeza, de indefinição, afinal, "as ideias são constelações eternas”. O Escrever pra quê? não teve a pretensão, portanto, de canonizar os saberes - e, tampouco, canonizar escritores/as com seu saber: o mundo já tem altares demais!; antes, pretendeu-se experiências de ignorãças, seguindo enquanto poesia da acolhida, da escuta, da (des)invenção.

Seduzidos/as liricamente em histórias onde "o descomeço era o verbo" (BARROS, 2010, p. 301), refletimo-nos em devires conectados a processos de desterritorialização, tentando pensar a escrita em suas múltiplas possibilidades (dentro e fora do vivido referencial canônico-europeu) e a nós mesmos/as como transeuntes, afinal, de que nos serviria repetir os caminhos de colonização social/linguístico/intelectual, por vezes subjacentes às parcerias estratégicas da lusofonia? Nós, humanidade, estamos sempre lutando por tantos territórios (dos afetivos aos geográficos) e pulsando entre tantas batidas de homogeneização e diversificação socioculturais a qualquer custo, que fico imaginando como seria/será possível uma ideia de "integração" numa sociedade cujo modelo de globalização acena/aceita invariavelmente para/os preceitos de um capitalismo perverso e multifacetado.

Nossos multilinguismos e multiculturalismos cotidianos na Oficina, de outro modo, fizeram-nos andar como transeuntes atlânticos que se fiaram por linhas de encontro, trançadas em fios multicores e em línguas sem arremate. Tentamos construir "linhas de fuga" e linhas de convivência atravessadas por experiências com a escrita - esta coisa feita de imagens moles e linhas flexíveis, fluidas, destreinadas. E escrevemos com pensamentocorpo/afeto/dor/alegria/incerteza e tudo o mais que não soubemos... 


\section{TOCANDO LA PIEL DE LA ESCRITA: LÍNEAS DE NOSOTROS-BRASIL Y NOSOTROS-ÁFRICA}

RESUMEN: Pensando en estaciones e ideas que recuerdan afectos, este artículo tiene por objetivo presentar experiencias con escrituras literarias por caminos que movilizaron caminos del Atlántico sur a partir de un taller realizado en el año 2016 - que, titulado ¿Escribir para qué?, fue vivenciada por estudiantes de Brasil, Santo Tomé y Príncipe y Guinea-Bissau, en la Universidad de la Integración Internacional de la Lusofonía Afro-Brasileña (Unilab-CE). Pasando por discusiones en torno a las políticas de escritura y escritura (RANCIÈRE, 2017; DELEUZE; GUATTARI, 2011), lectura (ZUMTHOR, 2014), literatura oral (CASCUDO, 1978; ALMEIDA, 2009), poética (BARROS, 2010) e lusofonía (BRITO; BASTOS, 2006), este estudio teórico-reflexivo intentó problematizar los matices metodológicos y vivenciales de ese taller acogidos en la idea de construcción de "líneas de fuga" y líneas de convivencia atravesadas y compartidas por experiencias con la escritura y el miedo de escribir a lo largo de la trayectoria literaria de un grupo de escritores.

PALABRAS-CLAVE: Escribir; Escritura; Lectura; Miedo.

\section{REFERÊNCIAS}

ALMEIDA, Maria Inês de. Desocidentada: experiência literária em terra indígena. Belo Horizonte: UFMG, 2009.

A-MI, Jo. Prefácio. In: A-MI, Jo; MENEZES, Maria Rosa [et. Al]. O que contam os sentidos. Fortaleza: Arte Visual Gráfica, 2016.

ANDRADE, Carlos Drummond de. A rosa do povo. 21 a ed. Rio de Janeiro/ São Paulo: Editora Record, 2000.

ASSARÉ, Patativa do. Antologia poética. 5a ed. Fortaleza: Demócrito Rocha, 2007.

. Ispinho e fulô. Fortaleza: Secretaria de cultura, turismo e desporto/Imprensa oficial do Ceará, 2001.

BARROS, Manoel de. Poesia completa. São Paulo: Leya, 2010.

BENJAMIN, Walter. Origem do drama trágico alemão. 2a. ed. Belo Horizonte: Autêntica, 2016.

BRITO, Regina Helena Pires de; BASTOS, Neusa Maria Oliveira Barbosa. Dimensão semântica e perspectivas do real: comentários em torno do conceito de lusofonia, p. 65-77, In: MARTINS, Moisés de Lemos; SOUSA, Helena; CABECINHAS, Rosa (orgs.). Comunicação e lusofonia: para uma abordagem crítica da cultura e dos media no espaço lusófono. Porto: Campos das Letras, 2006.

CÁ, Ianes Augusto. Escrever pra quê? In: A-MI, Jo; MENEZES, Maria Rosa [et. Al]. O que contam os sentidos. Fortaleza: Arte Visual Gráfica, 2016. 
CÁ, João Fernando. Um precisa do outro. In: A-MI, Jo; MENEZES, Maria Rosa [et. Al]. O que contam os sentidos. Fortaleza: Arte Visual Gráfica, 2016.

CASCUDO, Luís da Câmara. Literatura oral no Brasil. $2^{a}$ Ed. Rio de Janeiro: José Olympio, 1978.

CUNHA, Antônio Geraldo da. Dicionário Etimológico. $2^{\mathrm{a}}$ Ed. Rio de Janeiro: Nova Fronteira, 2001.

DELEUZE, Gilles; GUATTARI, Félix Mil platôs: capitalismo e esquizofrenia 2. Vol.1. São Paulo: Editora 34, 2011.

DICIONÁRIO HOUAISS: sinônimos e antônimos. SP: Publifolha, 2008.

DIDI-HUBERMAN, Georges. Sobrevivência dos vaga-lumes. Belo Horizonte: UFMG, 2011.

DODÓ, Mykele. IVO. In: A-MI, Jo; MENEZES, Maria Rosa [et. Al]. O que contam os sentidos. Fortaleza: Arte Visual Gráfica, 2016.

GOMES, Nilma Lino; VIEIRA, Sofia Lerche. Construindo uma ponte Africa-Brasil: a Universidade da Integração Internacional da Lusofonia Afro-Brasileira (UNIL AB). Lisboa: Revista Lusófona da Educação, n.24, 2013.

NEUPARTH, Sofia. Que corpo é este? Que arte é esta? In: NEUPARTH, Sofia; GREI-

NER, Christine. (orgs.). Arte agora: pensamentos enraizados na experiência. São Paulo: Annablume, 2011.

PACHECO, Carlos. Lusofonia e regimes autoritários em África. Público (site): Lisboa, 3 de Fevereiro de 2000. Disponível em: https://www.publico.pt/2000/02/03/jornal/lusofoniae-regimes-autoritarios-em-africa-139518. Acesso em: 23 de abril de 2018.

PINHEIRO, Carlos Eduardo. O limite do prazer. In: A-MI, Jo; MENEZES, Maria Rosa [et. Al]. O que contam os sentidos. Fortaleza: Arte Visual Gráfica, 2016.

RANCIÈRE, J. Políticas da escrita. 2a ed. São Paulo: Editora 34, 2017.

. O espectador emancipado. São Paulo: Editora Martins Fontes, 2012.

ZUMTHOR, Paul. Performance, recepção, leitura. São Paulo: Cosac Naify, 2014.

WILL, Silvia. O menino que contrariou a lua. In: A-MI, Jo; MENEZES, Maria Rosa [et. Al]. O que contam os sentidos. Fortaleza: Arte Visual Gráfica, 2016.

Recebido em: 31/05/2018.

Aprovado em: 30/07/2018. 